\title{
Proyectos socioacadémicos: la práctica de la responsabilidad social en el ISECENSA
}

\author{
Ángela Barros Fonseca Berto*
}

\begin{abstract}
Resumen
El foco de este estudio es la práctica de la Responsabilidad Social (RS) en una Institución de Enseñanza Superior —el ISECENSA—, que se encuentra en Los Campos dos Goytacazes/RJ. Comprendemos por RS Universitaria, la capacidad que tiene la universidad de difundir y poner en práctica un conjunto de principios y valores, por medio de cuatro procesos esenciales: Gestión, Enseñanza, Investigación y Extensión, comprometiéndose así desde el punto de vista social, con la comunidad universitaria y con el propio país. Esta investigación cualitativa — estudio del caso- interpreta los proyectos de RS practicados en el ISECENSA, utilizando como muestra cinco proyectos socio académicos desarrollados en el periodo 2006-2008. Es posible concluir que el alejamiento del primer sector (organizaciones estatales) de la RS contribuye al avance de las acciones del tercer sector y las prácticas de RS se vuelven una constante en las instituciones.
\end{abstract}

\section{Palabras clave}

Responsabilidad Social. Proyectos socioacadémicos. Universidad. Gestión.

\begin{abstract}
The focus of this study is the practice of social responsibility in an Institution of Higher Education - the ISECENSA, located in Campos dos Goytacazes / RJ. We understand that the University's Social Responsibility means the ability of disseminate and implement a set of principles and values, through four key processes: management, teaching, research and extension, committing by the social point of view, with the university community and the country itself. This qualitative research - the study of the-interprets the projects carried out in the Social Responsibility ISECENSA. It's used as a sample, five social and academic projects developed between 2006 - 2008. It can be concluded that the removal of the first sector (government agencies) regarding social responsibility contributes to the advancement of the actions of the third sector and social responsibility practices become a constant in the institutions.
\end{abstract}

\section{Key words}

Social Responsibility. Social and Academic Projects. University. Management.

Forma sugerida de citar: Barros Fonseca Berto, Ángela. 2011. "Proyectos socioambientales. La práctica de la responsabilidad social en el ISECENSA". Universitas 14. Enero/Junio. Pp. 99-123.

Maestra en Educación (Universidad Politécnica Salesiana). Profesora del Curso de pedagogía de los Institutos Superiores de Enseñanza del Centro Educacional Nuestra Señora Auxiliadora (ISECENSA). angela.berto@ibest. com.br 


\section{Introducción}

Hay mucho que discutir dentro de las instituciones sobre RS. También en las de enseñanza superior la cuestión se concentra en cómo viabilizar prácticas de RS unidas al mundo académico.

Entre esas organizaciones está el Instituto Superior de Enseñanza del Centro Educacional Nuestra Señora Auxiliadora (ISECENSA), ubicados en Campos dos Goytacazes, RJ, Brasil. Es al interior de esa institución de enseñanza superior particular que investigaremos las siguientes cuestiones: ¿De qué manera ocurren los proyectos de RS en el ISECENSA? ¿Cómo se aproxima a esos proyectos la idea de "prevención" trabajada en las instituciones salesianas? ¿Las actividades direccionadas a la comunidad de los Campos dos Goytacazes (externa) están relacionadas a las trabajadas en el ISECENSA (interna) —Plan de Desarrollo Institucional (PDI)—? ¿Las acciones desarrolladas se caracterizan como componentes de la malla curricular de los cursos; o sea, se vuelven elementos del dominio cognitivo trabajados en estrategias didácticas relacionadas a las acciones desarrolladas en el campo?

Dentro de este contexto percibimos que la sociedad está exigiendo, cada vez más, que también las universidades necesitan rendir cuentas sobre la manera cómo capacitan a sus estudiantes para evitar futuros casos de corrupción y para que tengan mejor conciencia social. Estas serán las universidades cuya contribución al desarrollo de la humanidad será reconocida por la sociedad.

En los últimos años, creció en importancia la Responsabilidad Social Universitaria (RSU) en los diferentes medios académicos, dada sus contribuciones para la formación de estudiantes y comunidades socialmente responsables.

Según François Vallaeys (2006: 39):

[...] la Responsabilidad Social Universitaria exige, a partir de una visión holística, la articulación de las diversas partes de la institución, en un proyecto de promoción social de principios éticos y de desarrollo social equitativo y sustentable, y la formación de profesionales ciudadanos igualmente responsables. ${ }^{1}$

1 Como ejemplo de Responsabilidad Social Universitaria en América Latina se nombra la muy interesante experiencia chilena Universidad Construye País, que integra varias universidades alrededor de un proyecto basado en una visión integral de responsabilidad social en el ámbito de la universidad (cubriendo los aspectos de gestión, docencia, investigación y extensión): http://www.construyepais.cl 
En el lanzamiento del libro A Universidade Necessária, Ribeiro (1975) apuntaba la necesidad de convertir a la universidad en un instrumento acelerador del proceso y de la revolución social y afirmaba que el mayor reto consistía en desarrollar un modelo teórico de universidad capaz de revertir su papel tradicional de perpetuar el sistema predominante, convirtiéndola en un agente de transformaciones de la sociedad.

Actualmente vemos que el escenario de la educación superior brasileña está pasando por profundos cambios desde la institucionalización del mercado universitario, que se caracteriza por la feroz competencia entre las instituciones para atraer clientes-consumidores (Calderón, 2006).

En el inicio de la década del noventa, en Brasil, se veía el impresionante crecimiento cuantitativo de las universidades particulares con fines lucrativos, gestionadas como empresas que ofrecen productos y servicios de acuerdo con la demanda del mercado. Son las universidades que favorecieron la democratización del acceso a la enseñanza superior, ampliando significativamente la oferta de productos educacionales. Sin embargo, el proceso de mercantilización de la enseñanza viola valores culturales fuertemente arraigados en el país, según los cuales la enseñanza es concebida como derecho social, un servicio brindado por el Estado con objetivos esencialmente públicos y sin fines lucrativos.

La RS, lejos de ser solamente asistencialismo/filantropía, debe ser en la actualidad propiedad social, política y educacional. Las acciones de filantropía, motivadas por razones humanitarias, son aisladas y recreativas, mientras que el concepto de RS posee una amplitud mucho mayor. La diferencia entre las dos, según el Instituto Ethos de Empresas y Responsabilidad Social, institución brasileña que se dedica a diseminar la práctica de la RS empresarial, y la de que, mientras la RS hace parte del planeamiento estratégico, trata directamente de los negocios de la empresa y de cómo ella nos conduce y es el instrumento de gestión, la filantropía es solamente la relación social de la organización para con la comunidad (Instituto Ethos, 2002).

No se trata de filantropía o caridad, pero sí de un compromiso de las organizaciones para crear asociaciones entre el sector público, el privado y el tercer sector. Más consciente de su papel, las organizaciones privadas se comprometen y comparten con el Estado la responsabilidad de minimizar la exclusión social, moviendo recursos para proyectos sociales. Además de eso, las 
instituciones socialmente responsables deben investir en la educación, la salud, el bienestar y el progreso/crecimiento de sus funcionarios, una vez que esos factores generan mayor productividad, compromisos y dedicación por parte de ellos. En suma, ser una empresa/institución responsable significa ejercer el papel social externo y completo, buscando una sociedad más justa y que promueva el desarrollo humano.

El problema que este estudio tiene como foco de análisis es verificar de qué manera son organizadas y cómo ocurren las actividades direccionadas para la RS en el Instituto Superior de Enseñanza del CENSA, llevando en consideración la premisa de que la institución está al servicio de la comunidad que busca participar de la construcción de un mundo mejor para todos.

Tenemos como objetivo investigar las prácticas de RS desarrolladas en 5 proyectos ejecutados en el periodo 2006-2008, en cursos de graduación, en el ISECENSA; comprender el concepto de RS redefiniendo el nuevo papel de la universidad; identificar en los proyectos analizados las actividades de RS que favorecen el protagonismo de los alumnos universitarios y la autonomía de los sujetos en el medio, cómo se manifiesta la RS (interna/externa) en el ISECENSA, a partir de los principios indicadores de la RSU.

En el ISECENSA se establece un compromiso a partir de los principios indicadores en el cotidiano de la institución, llamados Proyectos Socioacadémicos, que se generan a partir de un trabajo conjunto de los profesores y entre profesores y coordinadores de curso y, luego, con los alumnos. Parten de una situación-problema enfrentada por la comunidad y que merece atención especial de la universidad. Al iniciar el periodo lectivo, los alumnos son involucrados en esos proyectos, fortaleciendo a los equipos ya existentes y motivándolos al trabajo voluntario y al ejercicio de la ciudadanía.

Como una institución salesiana, es posible percibir que el ISECENSA se preocupa en volver real el Sistema Educativo de Don Bosco en la óptica de la prevención. Los proyectos socioacadémicos proporcionan oportunidades de crecimiento tanto para los universitarios como para la comunidad local.

En el Sistema Educativo de Don Bosco, la prevención es el gran referente para la actuación del educador junto a los alumnos. Les permite liberar sus mejores energías, aprovechar de la mejor manera los caminos más sustanciosos de la educación. Así, dentro de las escuelas salesianas, la acción pedagógica com- 
prometida con la formación del buen cristiano y del honesto ciudadano, debe poner como principios que orienten la práctica educacional — según el artículo 43 de la Carta de Principios- - El respecto a la dignidad de la persona humana; la garantía a la igualdad de derechos; el incentivo a la participación y el cultivo de la solidaridad, que se traduce en la apertura a las personas, en compartir el empeño en la transformación de la realidad.

\section{Desarrollo}

\subsection{EI concepto de RSU}

Comprendemos por RSU la capacidad que tiene la universidad de difundir y poner en práctica un conjunto de principios y valores, por medio de cuatro procesos esenciales: Gestión, Docencia, Investigación y Extensión, cuyo compromiso se cumple desde el punto de vista social, con la comunidad universitaria y con el país en el que interviene (De la Jara et al, 2006).

El término responsabilidad social se generalizó en la última década, en la medida en que se volvió uno de los pilares de sustentación del llamado Tercer Sector. El Tercer Sector es un movimiento social que predica la corresponsabilidad entre el Estado y la Sociedad Civil para equiparar los principales problemas sociales, frente a la crisis fiscal del Estado y del colapso del Estado de Bien-Estar (Calderón \& Marim, 2003).

El Sistema Nacional de Evaluación de la Educación Superior (SINAES) se fundamenta, entre otros aspectos, en la "profundización de los compromisos y responsabilidades sociales" de las Instituciones de Enseñanza Superior (IES); ${ }^{2}$ constando entre los principios fundamentales: "la responsabilidad social con la calidad de la educación superior".

Concretamente, la gran novedad está en la inclusión de la RSU como una de las diez dimensiones de evaluación de las IES. La interferencia estatal en el

2 Las diez dimensiones son: La misión y el PDI; la política para la enseñanza, la investigación, la pos graduación y la extensión; RS de la institución; la comunicación con la sociedad; las políticas de personal; organización y gestión de la institución-funcionamiento de los colegiados; infraestructura física; planeamiento y evaluación; políticas de atención a los estudiantes y sustentabilidad financiera. 
sistema universitario presentó nuevos elementos para la discusión de la cuestión de la RS: lo que era solo tendencia del mercadeo, ahora asume el carácter de obligación institucional frente a la norma estatal. Los SINAES, instituidos por la Ley 10.861 del 14 de abril de 2004, del Gobierno Federal, afirma que la RS se refiere a la contribución de las IES con la "inclusión social, el desarrollo económico y social, la defensa del medioambiente, la memoria cultural, la producción artística y el patrimonio cultural" (Brasil, 2006c:138 Apud Calderón, 2008: 23).

La extensión universitaria se define como dimensión del trabajo desarrollado por la academia en la enseñanza y en la investigación, en la formación de recursos humanos y en la producción y divulgación del conocimiento producido. No puede ser confundida con asistencialismo. La escuela no puede sustituir el Estado en la atención de las necesidades básicas de la población más necesitada. Es necesario evitar, por otro lado, que se siga confundiendo la extensión universitaria con acciones filantrópicas basadas en el trabajo voluntario de los alumnos, profesores y funcionarios; la llamada responsabilidad filantrópica (Todorov, 2005).

El trabajo de extensión solo se justifica a medida que la extensión es enseñanza y/o investigación: el alumno atiende a la población carente como parte de su aprendizaje práctico, sea en el ejercicio profesional, sea en el entrenamiento de sus habilidades de investigación. La RS está en todo lo que rodea la formación de los alumnos y la producción del conocimiento.

\subsection{El escenario actual}

En los últimos años creció en importancia la RSU en los diferentes ámbitos académicos, sobretodo en la enseñanza privada, dada su contribución para la formación de estudiantes y comunidades socialmente responsables.

Para Vallaeys (2006), es en la universidad que se forma el más alto nivel de cualificación de persona, desde el punto de vista técnico científico. Pero no siempre en ella se tiene formado el profesional ciudadano, comprometido con el cambio deseado por las sociedades como las de América Latina. Tal responsabilidad beneficia, pues, tanto a las organizaciones cuanto al entorno social en el cual ellas se insertan. 
Enseñanza, investigación y extensión son acciones privilegiadas en la enseñanza superior, ya que integran, inter y extra muros, conocimientos que están (o deberían estar) al servicio del aprendizaje, de enseñar y de promover. Aprender es enseñar, siendo sinónimos de una construcción colectiva del conocimiento. Promover siendo sinónimo de restablecer la dignidad y también el compromiso de uno con los demás. Representa un paso adelante en la intención del hacer, del servir, presupone una percepción más profunda del principio de la 'fraternidad' (ibíd., 2006).

Las instituciones de enseñanza superior no pueden distanciarse de ese movimiento de RS, que se fortalece en la misma proporción en el que se fortalece la sociedad civil brasileña, organizándose en la búsqueda de la construcción de un mundo más prospero, más humano, menos violento, con desarrollo económico más justo e igualdad de oportunidades para todos.

Reflexionar sobre la RSU significa pensar no solo en los deberes y en las obligaciones de la universidad, sino en las incumbencias inherentes a la naturaleza institucional de las IES, en la transparencia y en la ética en sus relaciones, en el respecto a la diversidad, en las buenas condiciones de trabajo y respecto a las normas democráticamente establecidas. Significa pensar sobre una institución que adopta una actitud ética en todas sus actividades y con todos los actores con las cuales interactúa, en los ámbitos interno y externo, además de las 'obligaciones morales' que la sociedad atribuye a los ciudadanos y las organizaciones sociales.

Cabe a la universidad facilitar el desarrollo de sus alumnos, pero es necesario reconocer que el desarrollo no es simplemente algo académico e informativo. Desarrollo consiste en crear condiciones favorables para que el estudiante aprenda a pensar por sí mismo; ayudarlo a fortalecer sus propios ideales y opiniones y promover la lectura de la realidad del mundo. Realidad que nos muestra un mundo donde existen más de mil millones de personas viviendo en una situación de pobreza y 10.815 millones desnutridas, entre otras cuestiones inconcebibles. Al exponer esta realidad, la universidad pasa a asumir su compromiso social y el estudiante empieza a comprender sus propias responsabilidades. Es aquí que la transformación se inicia: cuando se construye la universidad alrededor de un núcleo social y no como un proceso paralelo como el de la proyección social. En resumen, la RSU es la conexión entre dos 
mundos distintos: la universidad, con sus tecnócratas, docentes, estudiantes, misión, currículo, investigación y el resto de su equipaje - tanto deseado cuando indeseado- y la realidad de nuestros países, con su injusticia, su pobreza, sus antagonismos y su globalización.

La gran diferencia de una IES que ejerce la RSU con otra que no, es que la primera no está enfocada simplemente en las estrategias que va a utilizar con la comunidad de su entorno, sea por proyectos de extensión universitaria, sea por resultados de sus investigaciones académicas, sea por programas asistencialistas, sino en el concepto de educación asumido en su proyecto institucional, en las premisas adoptadas y en los presupuestos éticos evidenciados en su proyecto político pedagógico. La gestión de un proyecto político pedagógico comprometido con la RS exige el respecto a los principios del colectivo, la libertad comunicativa, el ejercicio corresponsable de la vivencia en común, y eso impone adecuaciones, reconfiguraciones, redimensionamientos de los procesos y de las formas del trabajo pedagógico.

Al contemplar en su PDI, el compromiso con la RSU, la IES amplía su función social más allá de la instrucción, asumiendo el compromiso de llevar a los estudiantes a ser lectores de su tiempo, usando sus conocimientos para actuar de manera edificada (De Sordi, 2005). Esto es, proponerse a transformarlos en protagonistas de su historia y constructores de su tiempo, detentores de una actitud más consiente, vigilante y crítica.

\subsection{La gestión de la RSU}

Las IES, en su mayoría, son emprendimientos educacionales con la misión de transformarse en espacios de formación y capacitación de los recursos humanos necesarios para el desarrollo del país. En este sentido, considerando esta finalidad institucional, hablar de la RSU significa hablar del compromiso permanente que las IES deberían tener para cumplir su misión, esto es, la garantía de una buena calidad de enseñanza para los ciudadanos que disfrutan de los servicios educacionales por ellas ofrecidos, sea en el ámbito de grado o de posgrado.

En este sentido, las estrategias de gestión de un proyecto pedagógico envuelve elementos tales como la formación continuada de docentes, la utiliza- 
ción de tecnologías de información y comunicación como una forma de democratización del acceso y la permanencia de los alumnos, la búsqueda de asociaciones y recursos para viabilizar proyectos sociales y de producción de conocimiento que mejoren los procesos de formación de sus cuadros y de sus comunidades más próximas.

Otro elemento importante en el proceso de construcción y afirmación de la identidad socialmente responsable de la IES es la creación de espacios de diálogo entre los diversos segmentos de aliados. La IES, como todo lugar donde se hace educación, es un espacio de encuentro de vivencias presentes, de formulación y expresión de expectativas y de construcción colectiva del futuro. De un futuro, necesariamente, mejor.

\subsection{La ética y la RSU}

La ética en las actividades es la base de la RS y se expresa por medio de principios y valores practicados por la organización.

El mundo vive acelerados procesos de cambio. Tiempo de incertidumbres. En este sentido, hablar de RSU significa hacer referencia a principios y valores direccionados a los desarrollos humanos que deben sustentar, iluminar y nortear a cualquier emprendimiento educacional que pueden ser agrupados en tres grandes dimensiones (De La Jara, 2006):

a. Dimensión universitaria: excelencia académica, compromiso con la verdad, independencia y transdisciplinariedad.

b. Dimensión personal: dignidad de las personas, integridad y honestidad, libertad.

c. Dimensión social: bien común y equidad social, desarrollo sustentable, aceptación y aprecio a la diversidad, sociabilidad y solidaridad, ciudadanía, democracia y participación.

El gran desafío está en transformar esos principios y valores en pilares que sustenten toda la estructura gerencial de las IES y orienten los proyectos de desarrollo institucional, pedagógicos y socioacadémicos de los cursos.

La preocupación es concretar esos principios y valores en el cotidiano de la vida académica, avalando las actividades en clases, las prácticas docentes, las relaciones gerenciales y las investigaciones científicas. 
Cuando discutimos sobre la RS, necesitamos hacer referencia a los principios y valores direccionados al desarrollo humano, condensados en los proyectos pedagógicos y en las directrices institucionales que deben sustentar, iluminar y nortear a las organizaciones del conocimiento, sus productos y servicios ofrecidos, incluyendo toda su estructura gerencial. Por lo tanto, es fundamental buscar la coherencia ética que debe existir entre el discurso y la practica administrativa y la académica en la educación superior. Hablar de RSU significa hablar de principios y valores. Las acciones comunitarias solamente poseen sentido si son direccionadas para lograr llegar a la misión de la IES. En eso, el sector privado de la educación superior tiene una responsabilidad que no puede ser aplazada, una vez que representa un $90 \%$ del total de las IES brasileñas, atiende aproximadamente a 2,7 millones de alumnos y tiene más de $70 \%$ de los alumnos matriculados del país como un todo (Calderón, 2006).

En ese contexto, las acciones comunitarias se tornan prácticas académicas por excelencia, que posibilitan no solamente el perfeccionamiento de las competencias técnicas, sino también el desarrollo de valores y principios direccionados al desarrollo humano. Las prácticas académicas no son solamente reflejos de estrategias de marketing institucional. Son, o deberían ser, reflejos de los principios y valores que apuntan a la praxis educacional de las IES, fruto del cumplimiento de su RSU.

Acciones de naturaleza asistencialista no van al centro de la cuestión, que es la promoción del desarrollo social sustentado. La filantropía se puede constituir en elemento adicional a la RS, pero no la sustituye (Schwartzman, 2005).

La ética debería constituir la esencia de la racionalidad económica. Tal constitución envuelve la RS de la institución privada, la responsabilidad ética de los medios de comunicación de masa, de las universidades, de las ONG, de los sindicatos y demás sectores de la sociedad civil. En América Latina hay una imperiosa necesidad de ampliar la agenda del debate de las décadas anteriores, superando la dicotomía económica-ética. Vivimos una "sed de ética" impregnando toda la sociedad (Troncoso et al., 2006). La universidad tiene la gran oportunidad de ponerse en la vanguardia de los esfuerzos que visionan a responder a tan justificado clamor.

La universidad puede cumplir un papel fundamental a este respecto situándose en el frente de la lucha por el conocimiento de la realidad. Podrá contribuir 
en la calidad del debate, por intermedio de investigaciones serias, rigurosas, de alto nivel, sobre los grandes temas de la pobreza y de la desigualdad que se encuentran en el centro de la vida cotidiana de la mayor parte de la población. La ética del desarrollo necesita ser activamente incorporada a su agenda, tanto en el campo de la investigación cuando en la formación de sus estudiantes de pregrado. Instruir éticamente implica nutrir al estudiante con experiencias reales de trabajo junto a la comunidad, de solidaridad activa, de voluntariado.

Una educación basada en el pensamiento complejo nos ayuda a entender mejor las razones de la perdida de la noción de responsabilidad en nuestra sociedad en la medida en que predomina un pensamiento compartimentado, fragmentado, que nos impide ver un todo complejo e interconectado.

Assman (2000) postula la idea de la interdependencia como hecho. Para él, la manera como nuestra vida transcurre diariamente nos lleva a pensar que somos individuos o grupos sociales autónomos e independientes y lo que pasa con el otro no nos llega y tampoco tiene que ver con nosotros.

El reconocimiento de la interdependencia entre todas las personas del mundo, entre todos los seres vivos y no vivos del planeta Tierra y entre todos los cuerpos celestiales del universo, nos hace ver que hay una interdependencia objetiva, esto es, independiente de nuestro reconocimiento o aceptación. Es la interdependencia como hecho. Todos nosotros sufrimos los efectos positivos o negativos de lo que pasa en el sistema en el cual vivimos (Assman, 2000: 81).

Nuestra tradición escolar, por infelicidad, nos preparó (y aun prepara) para conocer 'pedazos' independientes de la realidad. Las disciplinas funcionan casi siempre de manera autónoma, recordando la realidad o un aspecto de la misma. La realidad nos es presentada de manera fragmentada. En suma, no aprendemos a ver las relaciones de interdependencia. Y, como consecuencia, los problemas de los individuos y de los grupos sociales son comprendidos como problemas aislados, que dicen solamente a los interesados y que deben ser solucionados por estos, sin ninguna responsabilidad del resto de la sociedad.

El ser humano, como ser complejo que es, necesita una educación que le ayude a percibir la complejidad existente en nuestra vida social. Así, desarrolla- 
mos nuevos principios éticos que no pueden quedar solamente en formulaciones abstractas, sino que necesitan concretizarse en prácticas éticas. Concretamente, hablamos de la continua búsqueda de la excelencia como parte del ethos de la institución de enseñanza superior.

\subsection{La práctica de la ciudadanía y de la responsabilidad}

Organizar y participar en acciones comunitarias, proyectos socioacadémicos, entre otras, son maneras de involucrar a los alumnos en la búsqueda de alternativas para problemas reales de la comunidad en la que vive.

El ISECENSA promueve el ejercicio de esta ciudadanía en la medida en que abre la oportunidad de nueves experiencias voluntarias de servicio a la comunidad por medio de su Clínica Escolar y a través de sus proyectos socioacadémicos desarrollados al largo del año.

Para Subirats (2003: 67):

En los últimos años hemos observado que las sociedades que cuentan con tradiciones más sólidas de asociacionismo, que saben mantener sentimientos de comunidad y pautas de reciprocidad entre sus individuos, y que desde siempre entendieron el público como un terreno secularizado, compartiendo entre instituciones representativas y entidades cívicas, son sociedades que están mejor preparadas para enfrentar los desafíos del cambio de siglo.

De acuerdo con Subirats (ibíd.), ciertos desafíos relacionados con problemas que requieren perspectivas de actuación que no pueden ser abordados solamente a partir de la capacidad de actuación de los poderes públicos: sustentabilidad, consumismo, marginalización, necesitan del apoyo de las instituciones para obtener resultados más concretos y en un plazo menor.

Así, las comunidades que mantienen lazos más próximos de confianza y que entienden los problemas colectivos como de cada uno y no solo de los poderes públicos, son las que mejor están abordando los graves dilemas de nuestra sociedad actual. 
Para eso, es necesario entender el concepto de comunidad como "involucramiento de individuos, sentirse con, pertenecer, compartir, tener relaciones sociales significativas” (Subirats, 2003: 75).

Una persona se siente comunidad si consigue comprometerse. Una persona se siente comunidad si puede participar. Una persona se siente comunidad si está conectada. Envolvimiento, participación y conexión son, sin duda alguna, factores que ayudan a crear comunidad, a crear sentido de pertenencia (ibíd).

La universidad, como institución, puede ser considerada dentro de la comunidad si permite a sus miembros el involucramiento, la participación y la conexión. Hace mucho que oímos, principalmente en las instituciones salesianas, la expresión 'comunidad educativa', entendida como un agrupamiento de profesores, alumnos, padres y funcionarios que comparten ciertos objetivos y vínculos.

En las líneas orientadoras de la misión educativa de las Hijas de María Auxiliadora (FMA), cap. 3, artículo 58, refiriéndose al valor de la comunidad educativa, se resalta:
El elemento fundamental para asegurar una eficaz acción educativa y para dar respuestas concretas a las demandas y las necesidades de las nuevas generaciones, en un contexto siempre más globalizado e inte- lectual, es la presencia de una comunidad educativa. En ella, se busca la convergencia y la continuidad de las intervenciones educativas de modo de involucrar a los jóvenes, las educadoras, los educadores y los padres en el proyecto de educación cristiana según el estilo del carisma salesia- no (Líneas orientadoras de la misión educativa de las FMA, 2005: 43).

Don Bosco y María Domingas Mazzarello pusieron en primer plano el valor de la comunidad educativa. La dimensión comunitaria del carisma salesiano implica encuentro, colaboración y reciprocidad dentro del proceso educativo.

Los proyectos socioacadémicos desarrollados en la comunidad educativa del ISECENSA visionan la formación integral de la persona, en el horizonte 
del humanismo cristiano. Tal formación abre innúmeras posibilidades de involucramiento activo en la promoción de la justicia y, por lo tanto, en la transformación social para la construcción de una convivencia democrática.

La comunidad-universidad no puede quedar reducida a una institución transmisora de conocimientos. Necesita ser vista y entendida como un lugar de interdependencia con la comunidad local. De esta manera, partimos de la hipótesis de que toda comunidad quiere ser reconocida, como tal, internamente, pero también externamente. Por tanto, la participación en proyectos direccionados para la comunidad local es de fundamental importancia. La comunidaduniversidad y la comunidad local deben ser entendidas como ámbitos de interdependencia y de influencia recíproca (Subirats, 2003).

Para que tengamos comunidades socialmente más responsables, deberíamos tener comunidades más participativas. Desarrollar la comunidad también significa desarrollar la participación y el involucramiento con sus problemas.

[...] llamamos escuela-comunidad a aquellos centros caracterizados tanto por la fuerte implantación en el territorio y por una activa aceptación de su diversidad social, cuanto por una fuerte identificación de sus componentes con un proyecto de escuela bien definido (Subirats, 2003: 82).

En las palabras de Subirats (2003) concluimos que el fuerte sentido de comunidad combina con la capacidad de aceptación y convivencia con la diversidad. El desarrollo de acciones solidarias implica un ambiente de libertad en la cual cada uno se siente responsable por todos en un proceso natural de ciudadanía.

\subsection{Principios orientados de RSU}

La universidad actúa con base en tres funciones tradicionales (docencia, investigación y extensión) y en una actividad indispensable en toda organización, esto es, la gestión: conjunto de procesos y estructuras administrativogerenciales que posibilitan a la universidad atender su misión institucional. En el centro de estos cuatro procesos clave se encuentran los principios y valores, como un sol del sistema. Los principios y valores son faroles a orientar o guiar 
el comportamiento humano. Son, pues, fundamentales y permanentes en una universidad socialmente responsable. Pueden ser ordenados en tres niveles, de acuerdo con la propuesta chilena Construye País: 1. Principios y valores del plano personal, que envuelven la dignidad de la persona humana, la libertad y la integridad; 2. Principios y valores del plano social que se refieren al bien común y la equidad social, al desarrollo sustentable y el medioambiente, la sociabilidad y la solidaridad, la aceptación y reconocimiento de la diversidad y la ciudadanía, democracia y participación; 3. Principios y valores del plano universitario que incluye el compromiso con la verdad, la excelencia y la interdependencia y la transdisciplinariedad (Subirats, 2006).

\section{Metodología}

Se trata de una investigación cualitativa descriptiva —estudio del casopues lidiaremos con interpretaciones de la realidad social de los proyectos de RSU practicados en ISECENSA, escenario de la investigación.

La metodología de la investigación cualitativa-descriptiva, en este trabajo, permitirá identificar y analizar datos no mensurables, como motivación y expectativas de un determinado grupo, al poner en foco las percepciones de los coordinadores de los proyectos y de los participantes. El contacto directo y estrecho con el objeto de estudio - en este caso, los proyectos seleccionados y los sujetos - deben favorecer el conocimiento de influencias que los sujetos sufren del ambiente en el que se insertan. En este caso, la relación campo de desarrollo del proyecto/participantes, que puede ser esencial y determinante para la comprensión del fenómeno en estudio.

En esta investigación utilizamos como muestra 5 Proyectos Socioacadémicos desarrollados en el periodo 2006-2008 en los Cursos de grado en: Psicología, Pedagogía, Fisioterapia y Administración. Para la realización de la investigación utilizamos entrevistas semiestructuradas con los coordinadores y algunos participantes de los 5 Proyectos de RSU desarrollados en el ISECENSA y que son foco de este estudio. Utilizamos también el análisis de documentos históricos e institucionales — síntesis de los proyectos concedida por los coordinadores y el PDI-, que nos ayudaron en la búsqueda de los orígenes 
de los proyectos de RS del ISECENSA y de cómo esas prácticas vienen siendo desarrolladas en la institución.

Luego de la colecta de datos, realizamos la transcripción y el análisis de las palabras de los entrevistados, considerando los testimonios y componiendo las unidades de significado, el contexto en el que fueron puestas las ideas, la consistencia interna, la frecuencia y la extensión de los comentarios, la especificidad de las respuestas, para entonces levantar las categorías de análisis. Para eso, hicimos la muestra en la dimensión de los coordinadores, alumnos y de algunos miembros de la comunidad que participan de los proyectos, en un porcentaje de aproximadamente $10 \%$ de entrevistados para cada proyecto.

\section{Resultados}

En los testimonios de los entrevistados, la autonomía (tanto de los alumnos que ejecutan el proyecto cuanto la comunidad involucrada) es un elemento muy fuerte que se desarrolla durante la vivencia de los proyectos.

Nosotros desarrollamos las actividades, las preguntas. Nosotros prácticamente organizamos todo (Alumno 1-Proyecto Solidarizarte).

Hice cuadros hermosos, ¡ni yo mismo lo podía creer! Quiero hacer más. (Portador del virus VIH 3-Proyecto Solidarizarte).

La prevención trabajada en las instituciones salesianas se aplica a estos proyectos en la medida en que ellos favorecen el desarrollo de la autonomía de los sujetos involucrados tanto como ayuda a la comunidad local en la búsqueda de mejores condiciones de vida y subsistencia.

Uno de los principios y valores del plano personal de acuerdo con la propuesta chilena Construye País, se relaciona a la "formación de personas capaces de tener autonomía, razón y conciencia” (Jímenez de La Jara et al., 2006).

Según esta misma propuesta, "para que la dignidad humana alcance su expresión en la vida universitaria, es necesario que se creen condiciones en las que cada integrante de la comunidad pueda entregar, por completo, su colaboración original y propia de sus tareas" (ibíd. p. 66).

La contribución original y propia es sentida en los alumnos por la libertad que tienen para proponer actividades y realizarlas en los proyectos tanto en la 
comunidad — sea por la confección de jabones y otras artesanías, procesamiento de araruta, culinaria, al hacer las lloviznas - como al alfabetizar.

Tomamos como base el concepto de RS que utilizamos a lo largo de esta investigación y la universidad, la capacidad de difundir y poner en práctica el conjunto de principios y valores, por medio de cuatro procesos esenciales - gestión, docencia, investigación y extensión - comprometiéndose desde el punto de vista social con la comunidad universitaria y con el país en que se inserta (Jímenez de La Jara et al, 2006). Es posible percibir la aplicación de este concepto en los proyectos socioacadémicos del ISECENSA analizados en el periodo de 2006-2008.

Considerando una de las cuestiones a la que nos referimos en el inicio de esta investigación sobre si las actividades direccionadas hacia la comunidad de Campos dos Goytacazes (externa) están relacionadas a las trabajadas en el ISECENSA (internas) — PDI-, encontramos que hay profunda relación entre ellas.

Las acciones de gestión interna de RSU de ISECENSA promueven el respecto al bienestar de los empleados, como las actividades de corrección postural desarrolladas por los alumnos de la Clínica-escuela de Fisioterapia, los profesores son motivados a diario por la acogida propia de las instituciones salesianas, reciben remuneración digna por el trabajo que ejercen, además de participar activamente en los proyectos socioacadémicos desarrollados en la institución.

Para De Sordi (2005), los compromisos con la formación y desarrollo de los ciudadanos reclama espacios institucionales que respeten los miembros de su comunidad interna, que sepan lidiar positivamente con las diferencias existentes, aprendiendo con la experiencia plural. Es lo que percibimos en los fragmentos de los entrevistados:

La institución (ISECENSA) es bien vista. Las personas hablan de los proyectos de aquí" (Alumno 2-Proyecto Solidarizarte).

La RS en el ISE, como práctica en los cursos existentes, es un vector creciente, algo que viene paulatinamente siendo interiorizado como una estrategia pedagógica que une lo útil a lo necesario (Coordinador-Proyecto Desvendando Rio Preto). 
A lo largo de esta disertación, discutimos sobre la creación de espacios de diálogo como un importante elemento en el proceso de construcción y afirmación de la identidad socialmente responsable de la IES.

Para Vallaeys (2006), el comportamiento de una institución con la RS benéfica, debe ser tanto con las organizaciones cuanto con el entorno social en el cual ellas se insertan. En los proyectos socioacadémicos hay ganancias de aprendizaje para ambas partes, pues en ellos se establece una relación de complementariedad, presupuesto básico, y la buena convivencia y realización de la colectividad humana.

Me gusta cuando ellas vienen aquí. El tiempo pasa más rápido. Nos reímos bastante (Portador del virus VIH-Proyecto Solidarizarte).

Me encantó el personal que vino a trabajar con nosotros. Son muy divertidos y halagan lo que hacemos (Residente 3-Proyecto Desvendando Rio Preto).

Ellos nos tratan muy bien (Presa 3-Proyecto Isecempre-Educando para a Liberdade).

Me quedo feliz al realizar un proyecto tan importante para la vida de las personas (Alumno 4-Proyecto Ética e Responsabilidade Social).

Queremos que los alumnos vuelvan. Nuestro día es distinto cuando ellos están aquí (Detenido 1-Campo de actuación 3-Proyecto Ética e Responsabilidade Social).

Me pasé feliz con ellos aquí. Nos tratan con respecto (Detenido 2-Campo de actuación 3-Proyecto Ética e Responsabilidade Social).

A partir de los testimonios citados podemos interferir que una buena relación alumno-comunidad es fundamental para la existencia de la confianza mutua.

Ambos, Don Bosco como Mazzarello, pusieron en primer plano el valor de la comunidad educacional. La dimensión comunitaria del carisma salesiano implica encuentro, colaboración y reciprocidad dentro del proceso educativo.

La existencia de comunidades más socialmente responsables depende de comunidades más participativas y que se involucren con los problemas de su 
entorno. Para eso, es necesario entender el concepto de comunidad como el involucramiento de los individuos "sentirse con, pertenecer, compartir, tener relaciones sociales significativas" (Subirats, 2003: 75).

La comunidad-universidad y la comunidad local, son aquí entendidas como ambientes de interdependencia y de influencia recíproca (ibíd. 2003)

Fue algo que nos marcó a nosotros y a los niños. Tengo la conciencia de que necesito hacer más (Alumno 4-Proyecto Ética e Responsabilidade Social).

Los proyectos de RSU del ISECENSA ocurren de manera diversificada, buscando unir la enseñanza, la investigación y la extensión a través de sus estrategias y del desarrollo con la comunidad local.

El ISECENSA mantiene lazos más próximos de confianza con la comunidad local; al desarrollar sus proyectos socioacadémicos comprende los problemas colectivos y aborda mejor los graves dilemas que la sociedad presenta, ejerciendo así su RS.

\section{Consideraciones finales}

La RS se traduce en una nueva política de gestión en las organizaciones, minimizando los impactos y los efectos que son generados a diario dentro y fuera de la institución, responsable ésta por las consecuencias sociales inducidas por la misma operación de organización. Este nuevo modelo de gestión se basa en fines éticos, justos y sustentables de desarrollo social y tienen el deseo de promover normas y reglamentos.

El alejamiento del Primer Sector (organizaciones estatales) frente a la RS, contribuye al avance de las acciones del Tercer Sector y las prácticas de RS se vuelven una constante en las instituciones, especialmente las particulares. Las universidades, por conocer de cerca la comunidad y sus proyectos, pueden dar respuestas más concretas a sus problemas, respetando las peculiaridades éticas y culturales de cada región.

Los proyectos desarrollados en el ISECENSA abarcan principios y valores del plano personal, social y universitario que, aplicados a la gestión responsable, la investigación, la docencia y la extensión, dejan la filantropía, generando un nuevo modelo de gestión basado en fines éticos, justos y sustentables de desarrollo para su comunidad interna y externa. 
Vimos cuánto se exige hoy de las IES: que sean emprendimientos educacionales con la misión de tornarse en espacios de formación y capacitación de los recursos humanos necesarios para el desarrollo del país. Y, en este sentido, garantizar una enseñanza de calidad a sus alumnos permitiéndoles la vivencia de oportunidades para el ejercicio de la ciudadanía, autonomía y creatividad es contribuir a que exista una actitud de involucramiento en la resolución de los problemas y para responder a las demandas de la comunidad en la que está insertado.

Es posible concluir que el papel de la universidad se vuelve más estratégico y decisivo. El ISECENSA tiene prácticas reconocidas de RS, interna y externamente, gracias a su gestión responsable y los proyectos socioacadémicos que desarrollan sus alumnos con la comunidad local, promoviendo la autonomía, el ejercicio de la ciudadanía, la calidad de vida, la generación de renta y una relación de reciprocidad y enriquecimiento mutuos entre sus alumnos y la comunidad.

Los proyectos socioacadémicos desarrollados por el ISECENSA se vuelven prácticas académicas por excelencia, que posibilitan no solamente el perfeccionamiento de las competencias técnicas, sino también el desarrollo de valores y principios direccionados al desarrollo humano.

De acuerdo con la propuesta chilena Construye País (Jiménez de La Jara, 2006), tales valores y principios son faroles que orientan y guían el comportamiento humano. Son fundamentales y deberían volverse permanentes en una universidad socialmente responsable, en la medida en que reconoce la mutua necesidad de interactuación entre la universidad y la sociedad, mediante un diálogo constante. La sociedad afecta a la universidad, la influye y la condiciona; la universidad coopera con la sociedad, dedica sus talentos y habilidades para generar conocimientos que la beneficien y le sean útiles. En una sociedad globalizada, la universidad no puede estar aislada de la realidad de su entorno.

El ISECENSA, teniendo como misión la formación de personas libres, responsables, abiertas al transcendente, mueve sus acciones estimulando actividades de cooperación técnico-científica, programas de incentivo a la producción académica, formación científica del docente, políticas de educación inclusiva, adecuando también su estructura física para portadores de necesidades especiales. 
Al desarrollar el Proyecto Solidarizarte fortalece una asociación con la Casa Irmãos da Solidariedade que viene mejorando la calidad de vida de los 42 pacientes portadores del virus VHI, internos en esta institución, pasando de la retórica de la RSU a la práctica efectiva de acciones que tienen, en el humano, su principal referente, integrando a los estudiantes del Curso de Pedagogía con los internos.

El Proyecto ISECEMPRE-Educando para a Liberdade hace de la alfabetización el principal instrumento de liberación de las internas del presidio Carlos Tinoco, ampliando las posibilidades de supervivencia en una sociedad para la cual la alfabetización es condición primordial. Por medio de las actividades de generación de renta, las presas vislumbran su propia subsistencia cuando alcancen su libertad, y los alumnos del curso de Pedagogía prueban romper paradigmas y prejuicios.

Incentivando el desarrollo endógeno en el pequeño pueblo de Rio Preto, el Proyecto Desvendando Rio Preto se preocupa por el desarrollo sustentable y del ambiente, además de desarrollar prácticas de ciudadanía, democracia y participación en la relación establecida entre los alumnos del curso de Administración y la comunidad.

El Proyecto Ética e Responsabilidade Social sensibiliza a los alumnos del curso de Psicología para una actuación más allá de la clínica, dando la oportunidad de un mayor contacto con la desigualdad social y promoviendo acciones de ciudadanía en los medios en el que actúan.

Los servicios que la Clínica-escuela de Fisioterapia presta a la comunidad local y regional, de manera gratuita, responde a las necesidades actuales de una sociedad diversa y carente de tal atención. El Proyecto Fisioterapia em Saúde Públida refleja el compromiso de la institución con la RS interna asegurando a sus estudiantes la calidad académica en su proceso de formación.

Analizando los testimonios colectados en las entrevistas realizadas con coordinadores de proyectos, alumnos y comunidad, percibimos la fuerte presencia de la autonomía cuando el ISECENSA ofrece a sus alumnos la libertad de pensamiento y acción en los proyectos en que participan; $R S$ interna y externa, cuando hacen una gestión responsable e incentivan la participación de la comunidad académica en los proyectos que desarrolla; calidad de vida, cuando vela por el bien común junto a las comunidades, promoviendo condiciones de 
dignidad; ejercicio de la ciudadanía y generación de renta, cuando se preocupa por la formación del alumno-ciudadano, pero también con la comunidad mediante las estrategias que son creadas para su propia supervivencia; relación de conocimiento y respecto alumno-comunidad, cuando se mantienen lazos de confianza con la comunidad local, al desarrollar sus proyectos socioacadémicos, entendiendo y abrazando los problemas colectivos.

Lazos que solo pueden ser construidos, con base en principios y valores humanos sólidos que permitan ver lo esencial que, muchas veces, se vuelve "invisible a los ojos, pero se ve bien con el corazón”, cuando nos aproximamos al otro, en una relación de interdependencia, considerándolo el sujeto de su propia historia, ciudadano libre y autónomo, comprometiéndonos con sus necesidades y volviéndonos eternamente responsables por lo que cultivamos.

Este trabajo quiere estimular a las comunidades académicas del ISECENSA para que continúen la práctica de sus proyectos socioacadémicos. El enfrentamiento de los males sociales depende del nivel de concienciación y articulación de todos los actores sociales. Las universidades o facultades reúnen el potencial intelectual e instrumental para el liderazgo de forma estratégica, sistemática, continua y eficaz en la solución de los problemas que afectan a la sociedad.

Quiere contribuir en la ampliación de la literatura existente sobre el tema de RS, que es una temática reciente en el escenario académico, especialmente en las IES.

Cabe a la universidad, que es mantenida con recursos del pueblo, tanto la pública como la particular, la responsabilidad de producir un conocimiento interactivo con los problemas humanos de la realidad moderna, y que este conocimiento esté dirigido, efectivamente, a mejorar la calidad de vida.

La realidad contemporánea presenta nuevos desafíos económicos, sociales y políticos, que necesitan ser, urgentemente, enfrentados por la universidad. La universidad no puede cerrar los ojos a la realidad sociocultural de nuestro país, debe ser un instrumento para promover la conciencia de que la producción de conocimiento solo tiene sentido cuando este está dirigido a la liberación y superación de las dificultades del ser humano, marcado por formas graves de injusticia y de marginación social y económica. 


\section{Bibliografía}

\section{Textos}

Assmann, Hugo. Competência e sensibilidade solidária: educar para a esperanza, Petrópolis: Vozes, 2000.

Brasil, Ministerio de Educación, Comisión Nacional de Evaluación de Educación Superior, Instituto Nacional de Estudios e Investigaciones Educacionales Anísio Teixeira, Evaluación Externa de las Instituciones de Educación Superior. Brasilia: INEP, 2006c.

. Ley 10.861, de 14 de abril de 2004. Ley del Sistema Nacional de Evaluación de Enseñanza Superior. Disponible en: http://portal.mec.gov.br/arquivos/pdf/leisinaes.pdf. Acceso el 15 de mayo de 2009.

Calderón, Adolfo Ignacio. Responsabilidade Social Universitária: contribuições para o fortalecimento do debate no Brasil, en Estudio, Año 24, No 36, 2006.

Doze premissas para a construção de uma Politica Institucional de Responsabilidade Social na IES, en Responsabilidad Social, ABMES, Año 3, No 3, 2008.

- Marim, Vlademir. Participação Popular, $A$ escola como alvo do terceiro setor, en Desafíos de la educación municipal. Donaldo Belo de Souza y Lia Ciomar Macedo de Faria (orgs.) Rio de Janeiro, DP\&A, 2003.

De La Jara, Responsabilidade Social Universitária: uma experiência inovadora na América Latina, en Estudios, Año 24, № 36, (et al., 2006).

De Sordi, María Regina L. A Responsabilidade Social como valor agregado do projeto político pedagógico dos cursos de graduação: o confronto entre formar e instruir, en Estudio, Brasilia, año 23, N.34. pp.29-39, 2005.

FMA, Para que tenham vida e vida em abundância. Líneas Orientadoras de la misión educativa das FMA, Torino: Elledici, 2005.

ISECENSA. Plan de Desarrollo Institucional (PDI), Campos dos GoytacazesRJ, Institutos Superiores de Enseñanza del Centro Educacional Nuestra Señora Auxiliadora, 2007. 
Ribeiro, Darcy. A universidade necesaria, São Paulo: Paz y Tierra, 1975.

Schwartzman, Jacques Responsabilidade Social no ensino superior, em Estudos, Brasilia, Ano 23, n.34, pp.47- 54, 2005.

Subirats, J. Educación: responsabilidad social e identidad comunitaria. In Goméz-Granell, C; Vila, I (Orgs.), La ciudad como proyecto educativo, Porto Alegre, ArtMed, 2003.

Todorov, João Cláudio. $O$ conceito de responsabilidade social nos estabelecimentos de ensino superior, en Estudio, Brasilia, Año 23, n.34, pp.41- 46, 2005.

Troncoso, Catalina Delpiano. Responsabilidade Social Universitária: uma experiência inovadora na América Latina, en Estudio, Año 24. № 36. Vallayes, François (2006), Que significa responsabilidade social universitária?, en Estudio, Año 24. № 36, (et al., 2006).

\section{Referencias electrónicas}

Instituto Ethos. Preguntas y respuestas. Disponible en: http://www.ethos.org. br/pri/princ/prespostas/index.asp>. Acceso: 21 marzo de 2008.

Envío 25 de febrero/2011 - aceptación 23 de mayo/2011 